\title{
The alternative history of a Victorian washstand set Meaning, Memory, Transitions
}

\author{
Introduction \\ My starting point for this paper is a Victorian jug, bowl and chamber pot set, that I \\ encountered displayed in the toilet of a small Yorkshire Museum. The story of this set \\ is the framework for an exploration of literature on how we invest personal, domestic \\ possessions with meaning.
}

Before starting its life in the museum, the jug, bowl and chamber pot set belonged to Mary, the secretary of the museum board. It was gifted to her by a friend four or five years ago, and she kept it in her bathroom filled with potpourri, dried flowers and soaps. When she had her bathroom replaced, there was no longer enough space to display the set. She moved it into storage in the shed, where she kept it on view to remind her that it needed a new home. Then she thought of putting it on display in the new museum toilet, on an old wooden cabinet she had in her conservatory. Her decision to move it out of her home and into the museum toilet was a creative and caring one, which triggered the washstand's transformation from a personal possession, into a public historical artifact.

The Victorian washstand set has an interesting -and in many ways ordinary- 'life' story, punctuated by transitions in meaning, value and purpose. By writing this paper I will visit the most significant transitions, and use these visits as the basis for considering literature that discusses peoples' relationships to their domestic possessions, and practices of keeping them that influence transitions in meaning. In particular, I am seeking instances where the physical and material properties of an object are discussed in relation to meaning-making.

The wider purpose of my research is to contribute to current debates on design and sustainable consumption. Current researchers and activists (see Thorpe 2010) identify a need for designers to infiltrate consumption, and find ways of challenging people's dependence on material goods to structure personal meaning. I want to extend the debate on design and consumption by examining the material influences on the ebb and flow of an object's meaning, during its life in the home. It is here that it is eventually decided whether the object is thrown away, whether it is divested of responsibly or not, and where attitudes to accumulation are acted out. What opportunities are there for designers to influence these individual, hidden processes of meaning-making?

Most of the research I refer to in this paper comes from or is informed by anthropology, where home possessions are now an established area of academic study. Seminal research from the 1980 s and 1990 s posits peoples' relationships to everyday objects and the home as subjects worthy of study, overturning academic views of objects as cultural 
symbols rather than as holders of personal meaning (e.g. Appadurai 1986, Attfield 2000, Cieraad 1999, Kwint 1999, Miller 1998). More recent research links home possessions, memory and meaning-making to everyday practices, creativity and human agency (e.g. Pink 2004, Hurdley 2013, Turkle 2011, Miller 2001 \& 2008). This, and related research, will be my means of contextualizing and understanding Mary's story, which I havestructured as four 'transitions' that describe its journey from functional and decorative household object, to museum artefact.

\section{Transition 1: household object to antique}

Mary was given her washstand set by a friend, an antiques dealer. She doesn't think it is an especially valuable set, nor does she have a special interest in acquiring antiques, but believes it was probably part of a job lot, and that he thought she might like it. Its function and decorative pattern suggest it may be late nineteenth century, although she has found no obvious markings to trace.

Prior to Mary's acquisition of the washstand set, its biography is unknown. Presumably though, it started life in the Victorian era as a functional, decorative household object, and has latterly become valued as an antique. Speculating about this transition provides clues about how the set is kept and valued now, and how the accumulation of goods became integral to constructing our homes.

The Victorian era was a period of huge economic, cultural and social change and a key period in our shift from a society whose patterns and practices were governed by religion and rigid social heirarchies, to one defined by individual autonomy and the cultivation of self-identity (McCracken 1990, Putnam 1995). Cohen (2006) discusses this shift in terms of peoples' relationships to their home possessions. She describes how Victorians overcame their discomfort with wealth and luxury by expressing religious and moral values through the material world. As previously static religious and social structures eroded, goods became perceived as agents of moral value that had the capacity to positively influence a person. People started to see themselves as individuals worthy of cultivation and to express self-identity through their choice and display of possessions (see also Bronner 1989).

Cohen describes how the late nineteenth century saw a surge in the collecting of old objects, which served as a means of distinguishing oneself from others through a form of object-connoisseurship. The relative rarity of old objects created rigid systems of worth, at a time when fixed distinctions of class and rank were rapidly eroding. Antiques become a "live" link to a nostalgically viewed past, and a material locus for collective understandings of history.

\section{Transition 2: Into Mary's home}

When Mary received the washstand set from her friend, she displayed it on a surface in the bathroom, and filled the pot with decorative soaps, the bowl with pot-pourri and the jug with dried flowers. She liked the set, and evidently saw decorative potential in it. She kept it there for a few years, until she replaced the bathroom.

The above paragraph describes a very ordinary occurrence of home decoration and display. It is nonetheless a valid point of departure for reviewing discussion of domestic possessions in the context of home décor and display, in order to illuminate it as part 
of a process of meaning-making. Practices of home decoration are well documented as processes of self-expression (see Gullestad 1993). Of relevance to my enquiry are discussions concerning the role of objects in home décor and display.

It is well established that the consumption of objects is a means of expressing and constructing self-identity (Belk 1988, Csikszentmihalyi \& Rochberg Halton 1981, Giddens 1991). Csikszentmihalyi and Rochberg Halton's seminal study views practices of displaying possessions as symbolic of personal meaning. Hurdley (2013) studies the mantlepiece as a display space with performative and ordering functions, enabling objects to be lifted above the ordinary run of things in the home, to give emphasis to their meaning, or to make them visible and therefore not forgotten. Similarly Miller (2008) discusses the ordering of possessions and meaning in relation to display. His narrative based analysis portrays how displays of domestic possessions are the visible expression of an underlying order of "things, values and relationships". He considers ordinary processes of selection and rejection, accumulation and display, as the structuring of our personal systems of understanding our place the world, or "cosmology". We cultivate our material environments in order to establish and understand how we fit in the world.

The above examples imply practices of cultivating meaningfulness through an ongoing process of display. However home décor can equally be a method of creating a pleasant atmosphere that supports everyday life. This perspective resonates with Mary's story, as she does not express a particularly strong emotional attachment to the set, but simply sees its decorative potential. Pink (2004) identifies a desire in British householders to create a 'homely' atmosphere in their bathrooms through the objects they keep. Pink is concerned not with the nature of display, but with the sensory experience of everyday practices of decoration and housework as processes of "constructing realities". Everyday practices of engaging with the material environment develop and reinforce meaning (Edwards 1999, Pink 2004). ${ }^{1}$

Birdwell-Pheasant and Lawrence-Zuniga (1999), Chevalier (1998), and Miller (2001) view the material domestic environment as an active agent that shapes our everyday practices. Others have discussed how objects and spaces communicate expectations of how we should interact with them. Long-standing historical processes and cultural values inform the ways in which we display things (Chevalier 1998). For example, a mantelpiece sets up an expectation of displaying objects (Hurdley 2013). Material agency is addressed in historian Edwards' (1999) detailed account of how the physical form of an object (in this case a photo frame) can set up an expectation of particular sorts of display and interaction.

\section{Transition 3: Into the shed}

The set stayed on display in the bathroom until Mary and her husband updated it with a new shower and units. Following this change there was no surface space left for displaying the set, and Mary moved it into storage in the shed. She didn't put it away in a box; rather she kept it out, visible, as a reminder to her to find it a new place. She would walk past it and think "oh what a shame.... [I] don't want it to get broken... what can I do?" She was reminded that the set had survived, intact and unbroken, for a long time. She tried to think of a new home for it, and thought of putting it in the museum but knew there was no room. 
During its period of limited display in the shed, the set became part of a different space and pattern of interaction. The shed is used for storing other surplus belongings, and Mary made the set visible as an intentional memory prompt. In her theory of "autotopography" Gonzalez (1995) describes collections of domestic possessions as maps of memory, history and belief, however, she is concerned only with objects of symbolic significance to individual identity. Graves (2012) takes a more extended view of the landscape of possessions we surround ourselves with to consider clutter; a kind of demarcated 'limbo' for objects yet to be subsumed into the order of the home. Graves refers to the mobile and fluid nature of meaning connected to clutter, and its capacity to 'speak' to us.

Mary placed the washstand in the shed so that it became a kind of mnemonic device, but there are other ways in which the set provokes remembrance. In my conversations with Mary she voluntarily described memories indirectly associated with the set; of using a washstand set during an overnight stay in Whitby in her teens, of a different washstand inherited from her mother, which she now keeps in the garden. Proust's emersive descriptions in "A la Recherche du Temps Perdu" of the involuntary evocation of memory (explored by Frayling 1999 and Kwint 1999) bring to life the complex embeddedness of objects in the process of remembering. According to Frayling, Proust attempted to understand how everyday goods are experienced and absorbed into everyday life. In Proust's text, sensory experiences of things (such as eating a madeleine) unlock a complex web of memories, which in turn are embedded in and supported by the material world. Objects can act as memory triggers via physical encounter (e.g. Mary's encounters with the set in the shed), as remembered objects (e.g. Mary's memory of using the washstand set in Whitby, and as additional triggered associations (e.g. the washstand Mary inherited from her mother and now keeps in the garden).

The set's transition to the shed was prompted by a rearrangement of the home interior, but it retained some value, as Mary actively sought a new home for it during its period in 'limbo'. The value she placed in it seems to be related in part to the fact of its survival; it has lasted a long time without getting separated or broken. Csikszentmihalyi \& Rochberg Halton (1981) identified fragile objects such as plates and cups as among the domestic objects most frequently mentioned as symbolic of ethnic and family roots. Building on these findings, designers Almquist and Lupton (2010) suggest that the fragility of the object sets up an expectation of breakage, and that consequent protective practices of use (ie treating it with care) may help build up or protect meaningfulness.

\section{Transition 4: Into the museum toilet}

During the period of keeping in the shed, Mary intentionally tried to think of a new place for the set. At around the same time, she rearranged the conservatory and decided she wanted to get rid of an old cabinet she kept gardening equipment in, which had once been her mother's. One day she had the idea that she could put the set into the museum toilet, on top of the old cabinet. The museum toilet is a single large cubicle, and the set and cabinet are placed in the corner. This means that when a visitor uses the facilities, they are in close proximity to the set and stand. Next to the washstand set Mary has placed a caption that describes the objects. It begins "This would have been your ensuite...".

Mary's decisions to rehome the set and to move it to the museum were caring. She looked after the set in the shed and clearly saw value in it, even though it doesn't appear to have had great personal meaning. This last transition was a creative means of releasing it from her possession, while making sure it was valued in its new home. Ordinary acts of dispossession have been described as a meaningful part of the process of self- 
construction and identification (Marcoux 2001, Isherwood and Douglas 1979). Crewe et al (2005) suggest that meaning and care is present to some degree in every decision to acquire or discard and argue that this challenges popular notions of a careless "throwaway society".2

Mary's decision was a response to several coinciding influences, which I see as material catalysts for her creative decision to move the set to the museum. Firstly, the changing environments of Mary's home and the museum both presented opportunities (the cabinet became available, as did the space in the toilet). Secondly, through its form, material and decorative qualities, the set communicated historical and functional associations that set up expectations of how it should be kept and valued. The story of the washstand set is a story of the dialogue between object, space, and human, and highlights both the agency of the objects and domestic spaces, and human creativity.

\section{Reflection}

The stand and set have undergone a final significant change in context, from a private home, to a public museum. Mary still sees them, and enjoys knowing that they are there. For museum visitors, they are historical artefacts that hold collective meaning. Mary's story is a very interesting example of the intersection of individual and collective meaning in one artefact. Narratives of ownership like this one interweave physical changes and evolving emotional associations, presenting us with a rich picture of the development of material meaning.

Mary's label in the museum refers to the washstand and set as an ensuite. This notion was linked in my conversations with Mary to her memory of cycling to Whitby as a teenager in the 1950s, and staying overnight in a B\&B where she used a stand and set, filled with cold water, in her room. Mary's siting and labeling of the stand and set is creative, and invites us (the visitors) to imagine ourselves into using the set, and subsequently into life in the Victorian era. Many visitors to the museum are students and school children unlikely to have experienced using a washstand and set. But Mary has, and in an indirect way she connects us to those memories.

Design research on sustainable user engagement (e.g. Mugge et al 2009) and emotional durability (Chapman 2005) tends to take a restricted view of the user-product relationship, by prioritising product semiotics and anticipating the user's purposeful interaction with the product. Viewing the life of the product in the user's possession as a series of transitions opens up this product-centric view to other social and material influences, and acknowledges the fluid and individual nature of the meaning attached to a product. It identifies critical points in the user-product relationship where the material circumstances of the product are connected to a shift in meaning and value. This could be a valuable means for designers to get at a richer set of understandings of the relationship between material and meaning.

The story of the washstand set reinforces research identifying the acquisition and wasting of possessions as acts of care. This suggests that encouraging users to keep things, on

\footnotetext{
${ }^{2}$ The notion of the throw-away society is the basis for critical work in design on the durability of products (Cooper 2010, Chapman 2005)

3 See Gant and Dean (2013) for an interesting example of design using co-production to connect personal memories to the product, and challenging perceptions of a waste material.
} 
the basis that products are carelessly wasted because they lack meaning, may not be wholly appropriate. Perhaps it is more pertinent to employ design approaches to 'hack' into existing user-product relationships, to reveal how we manage accumulation, to unpick our dependence on material things, and explore the complex embeddedness of objects in memory and human relationships. ${ }^{3}$

\section{References}

ALMQUIST, J. and LUPTON, J., 2010. Affording Meaning: Design-Oriented Research from the Humanities and Social Sciences. Design Issues, 26(1), pp. 3-14. APPADURAI, A., ed, 1986. The Cultural Biography of Things: Commoditization as Process. Cambridge: Cambridge University Press.

ATTFIELD, J., 2000. Wild things: The material culture of everyday life. Oxford: Berg Publishers. BELK, R., 1988. Possessions and the Extended Self. The Journal of Consumer Research, 15(2), pp. 139-168. BIRDWELL-PHEASANT, D. and LAWRENCE-ZUNIGA, D., eds, 1999. Houselife: Space, Place and Family in Europe. Oxford, UK: Berg. BRONNER, S.J., 1989. Consuming Visions : Accumulation and Display of Goods in America, 1880-1920. Norton: The Henry Francis Du Pont Wintherthur Museum.

CHAPMAN, J., 2005. Emotionally Durable Design: Objects, Experiences And Empathy. Earthscan. in an English Suburb. In: D. MILLER, ed, London, UK: UCL Press, pp. 47-72.

CIERAAD, I., ed, 1999. At Home: An Anthropology of Domestic Space. New York: Syracuse University Press. COHEN, D., 2006. Household Gods: The British and their Possessions. Yale University Press.

CHEVALIER, S., 1998. From Woolen Carpet to Grass Carpet: Bridging House and Garden COOPER, T., 2010. Longer Lasting Products: Alternatives To The Throwaway Society. Gower. CSIKSZENTMIHALYI, M. and HALTON, E., 1981. The Meaning of Things: Domestic Symbols and the Self. Cambridge University Press.

DOUGLAS, M. and ISHERWOOD, B., 1996 [first published 1979]. The World of Goods: Towards an Anthropology of Consumption. New York, USA and Canada: Routledge.

EDWARDS, E., 1999. Photographs as Objects of Memory. Material Memories: Design and Evocation. Oxford, UK and New York, US: Berg, .

FRAYLING, C., 1999. Preface. In: M. KWINT, C. BREWARD and J. AYNSLEY, eds, Material Memories: Design and Evocation. Oxford, UK: Berg.

Gant, N. and Dean, T., 2013. Mediating Material Narratives for Meaningful Products, Poetics and Praxis Research Through Design Conference, Northumbria University.

GIDDENS, A., 1991. Modernity and Self-Identity. Cambridge, UK: Polity Press.

GONZALEZ, J.A., 1995. Autotopographies. In: A. GORDON and M. RYAN, eds, Prosthetic Territories: Politics and Hypertechnologies. Boulder, Colorado, US and Oxford, UK: Westview Press, .

GRAVES, J., 2012. The Secret Lives of Objects. Victoria, Canada: Trafford.

GREGSON, N., METCALFE, A. and CREWE, L., 2005. Identity, Mobility and the Throwaway Society. Environment and Planning D: Society and Space, 25(4), pp. 682-700.

GULLESTAD, M., 1993. Home Decoraction as Popular Culture. Constructing Homes, Genders and Classess in Norway. In: T. DE VALLE, ed, Gendered Anthropology. London: Routledge, .

HECHT, A., 2001. Home Sweet Home: Tangible Memories of an Uprooted Childhood. In: D. MILLER, ed, Home Possessions. Oxford, UK: Berg, .

HURDLEY, R., 2013. Home, Materiality, Memory and Belonging: Keeping Culture

Palgrave Macmillan.

KWINT, M., BREWARD, C. and AYNSLEY, J., eds, 1999. Material Memories: Design and Evocation.Oxford: Berg. MARCOUX, 2001. The "Casser Maison" Ritual. Constructing the self by emptying the home. Journal of Material Culture,

MCCRACKEN, G., 1990. Culture and Consumption. Bloomington and Indianapolis, USA: Indiana University Press (Midland Books).

MILLER, D., 2008. The Comfort of Things. Polity Press.

MILLER, D., ed, Home Possessions Oxford: Berg.

MILLER, D., ed, 1998. Material Cultures. London: Routledge.

MUGGE, R., SCHOORMANS, J. and SCHIFFERSTEIN, H., 2009.

Emotional bonding with personalized products Journal of Engineering Design, 20(5), pp. 467-476.

PINK, S., 2004. Home Truths: Gender, domestic objects and everyday life. Oxford: Berg.

PUTNAM, T., 1995. Between Taste and Tradition: Decorative Order in the Modern Home. Bulletin of the John Rylands Library, 77(1), pp. 91-108.

THORPE, A., 2010. Design's Role in Sustainable Consumption. Design Issues, 2(26), 